\title{
LO JURÍDICO EN LA FILOSOFÍA LULIANA
}

\author{
José María Soto Rábanos \\ C.S.I.C. Madrid
}

\begin{abstract}
RESUMEN
Raimundo Lulio contempla el derecho, como toda otra realidad del mundo creado, desde una filosofía de fe, de fe cristiana, o sea, desde una forma de razonar en servicio de la teología, en cuanto que de ese razonamiento recaba los argumentos demostrativos de la fe cristiana. El derecho es una ciencia confusa, necesaria a los hombres por la ausencia de caridad. La actividad jurídica, que Raimundo Lulio demuestra conocer bien, le parece prolija y compleja en demasía: por ello, a través de su Arte, propone una metodología, un sistema simplificado y mecánico para aplicar el derecho y hacer justicia, fundamentado en principios teológicos y de derecho natural. Raimundo Lulio juega, en fin, a la utopía.
\end{abstract}

Palabras Clave: Raimundo Lulio, derecho, filosofía, utopía.

\section{ABSTRACT}

Raimundo Lulio sees law, and all created things in the world, from the philosophical viewpoint and the kind of reasoning favoring theology, since that reasoning gets the arguments to prove christian faith. Law is an unclair, although necessary, science, due to the absence of charity. To Raimundo Lulio, who seems to know this very well, the legalized activity is complex and complicated. And that's why he proposes in his Arte a guiding methodology, which is a simplified and mechanic system to apply law and do justice, based on principles of theology and natural law. Raimundo Lulio plays utopia.

Key words: Raimundo Lulio, law, philosophy, utopia.

\section{LO JURÍDICO EN LA FILOSOFÍA LULIANA}

Debo reconocer que he entrado con cierto temor reverencial en el estudio del pensamiento luliano sobre el mundo del derecho, y que son más los interrogantes que me he ido planteando durante su análisis que las respuestas que me he atrevido a proponer.

En esta primera incursión en tema tan delicado, me conformo con una serie de reflexiones a la luz de algunos textos lulianos significativos y de la bibliografía que he podido consultar.

Los estudios sobre aspectos jurídicos y sociojurídicos del pensamiento de Raimundo Lulio no son escasos; son más numerosos de lo que esperaba encontrar al proyectar este trabajo. Pero son pocos los analistas del pensamiento luliano que se han dedicado a estudiar directamente la doctrina jurídica de Raimundo Lulio, su filosofía jurídica, su visión «sabia» del mundo del derecho. 
En los años veinte y treinta, Andrés de Palma de Mallorea escribe sobre las ideas jurídicas de Lulio y su aplicación a las distintas ramas del derecho ${ }^{1}$ y Eugen Wohlhaupter desarrolla la relación de Lulio con la ciencia del derecho. ${ }^{2}$ Angel Francisco Brice, ya en los años cincuenta, realiza un breve estudio sobre el pensamiento jurídico de Raimundo Lulio. ${ }^{3}$ En los años sesenta, Francisco Elías de Tejada escribe sobre la metodología jurídica luliana; ${ }^{4}$ el mismo autor en los años setenta dedica una atención especial a. Raimundo Lulio en su libro Tratado de Filosofía del Derecho. ${ }^{5}$

Recientemente, Antonio Montserrat Quintana ha publicado un amplio trabajo sobre el tema, elaborado como tesis doctoral. ${ }^{6}$ Este autor demuestra un conocimiento poco común del pensamiento de Lulio y lleva a cabo un estudio en profundidad de la teoría jurídica luliana. Tiene, no obstante, algunos defectos de cierta importancia, según mi opinión, tanto de ámbito general como en aspectos concretos.

En general, me parece que el autor no se despega de ciertos tópicos, cayendo en la tentación de proferir de vez en cuando exclamaciones encomiásticas «devotas», y acientíficas, para valorar los méritos de Raimundo Lulio en determinadas cuestiones, ${ }^{7}$ y que se explaya demasiado, más de lo conveniente, en considerandos al margen de lo estrictamente jurídico, de manera que, a veces, se olvida el lector de que se halla ante un análisis de la visión luliana del derecho y no ante el de otra temática luliana.

En concreto, estimo que el autor debería haber contrastado algo más ciertas aseveraciones que efectúa con toda rotundidad, pero sin argumentación suficiente, a mi entender. Dos ejemplos.

La modalidad del derecho que Raimundo Lulio describe como «dret atrobat per cessar mal». ${ }^{8}$ Montserrat Quintana lo refiere «sensu lato» al derecho penal, ${ }^{9}$ en oposición a las otras dos ramas o

1 «Sistema juridic i idees juridiques del mestre Ramon Lull», en Estudis Franciscans 30 (1923), pp. 54-65 y 125138; dos años antes publicó unos estudios preliminares en Quaderns d'Estudi 13 (1921), pp. 32-50; estudios ampliados en la obra Els sistemes juridics i les idees juridiques de Ramon Lull, Palma de Mallorca, 1936.

2 «Ramon Lull und die Rechtswissenschaft», en Ernst Mayer Festschrift, Weimar (1932), pp. 169-202; «Ramon Lull, ein vorläufer des Postglossatoren», en Atti del Congresso Internazionale per il Diritto Romano, Bolonia-Roma abril de 1933, Pavia (1934), pp. 491-514; «Die ars brevis, quae est de inventione mediorum iuris civilis des Ramon Lull», en Miscel-lánia Lul-liana, Barcelona (1935), pp. 36-55.

3 Raimundo Lulio, su pensamiento jurídico, Caracas, (1951), $24 \mathrm{pp}$.

4 En Anales Cátedra Suárez de la Universidad de Granada, 1, (1961), pp 139-156.

5 Dos volúmenes, Sevilla, 1974 y 1977.

6 Títulado La visión luliana del mundo del derecho, Institut d'Estudis Baleàrics, Barcelona-Palma de Mallorca 1987.

7 Me refiero a frases al estilo de: «Llull se nos revela como un genio sin paliativos[...]» (p. 88); «[...]tan sugestivo como todas las ideas lulianas» (p. 196); «Ramón expone con palabras que no admiten vacilaciones»; «[...]en una serie de hermosas y breves sentencias, p. 200; «es la que en un rasgo genial[...]»; «[...]en su particular versión originalísima de énfasis»; «esta ecuación se hace posible desde la perspectiva grandiosa del precepto supremo del amor a Dios», pp. 204-205.

8 Doctrina Pueril, cap. 76, n. ${ }^{\circ 3}$. Este texto corresponde a la edición crítica de Gret Schib (colección «Els nostres clàssics», Barcelona (1972), p. 174. En la edición de 1906 (Obres doctrinals, de Mateu obrador y Bennassar, reedición facsímil, Palma de Mallorca, 1986, el texto es: «Sapies, fill, que una altra manera hi ha de dret, lo qual es atrobat per cessar mayor mal», p. 136; y en la Antología de Ramón Llull con prólogo y notas de Miguel Batllori, traducción y revisión crítica de Ana $\mathrm{M}^{\mathrm{a}}$ de Saavedra y Francisco de P. Samaranch, a quien corresponde la traducción de Doctrina pueril (Dirección General de Relaciones Culturales, Madrid, 1961) vol.II, p. 288, El texto es: «Debes saber, hijo mío, que hay aún otra modalidad de Derecho, creado para evitar otro mal mayor». A mi modesto entender, estas dos lecturas se avienen mejor con la interpretación ambivalente que propongo a continuación.

9 Montserrat Quintana, A, 178: «[...] y un tercer derecho que en sentido amplio podríamos considerar derecho penal». En esta consideración, afirma seguir la opinión de Andrés de Palma de Mallorca, Els sistemes juridics i les idees juridiques de Ramon Llull, p. 28. 
modalidades, es decir, al derecho canónico y al civil. ${ }^{10}$ No se plantea la posibilidad de que Lulio pueda referirse al conjunto de normas emanadas del poder temporal que no se avienen con el derecho divino, es decir, con el derecho natural y con el derecho positivo revelado (siempre a la luz del pensamiento teológico-filosófico cristiano), y que solamente se pueden justificar como solución al dilema de elegir o de consentir un mal menor para evitar un mal mayor ${ }^{11}$ lectura más cercana, en mi opinión, a lo que pretende señalar Lulio, y que no excluye la inclusión de las normas restrictivas de los derechos y de las libertades, y de las vindicativas de responsabilidades en general, o sea, del derecho penal. ${ }^{12}$

En otro lugar, el autor habla de giro copernicano y profunda originalidad por el hecho de que Lulio sustituye el principio general del derecho natural alterum non laedere por el precepto evangélico-teológico Deum diligere. ${ }^{13}$ Realmente, no veo en ello un giro copernicano ni originalidad profunda; en el Decreto de Graciano el mandato Deum diligere viene recogido como un precepto legal, como ejemplo de uno de los «oficios» de la lex: «Omnis autem lex aut permittit aliquid, ut: uir fortis petat premium; aut uetat, ut: sacrarum uirginum nuptias nulli petere liceat; aut punit, ut: qui cedem fecerit, capite plectatur; eius enim premio aut pena vita moderatur humana: ${ }^{14}$ aut precipit, ut: Dilige Dominum Deum tuum». ${ }^{15}$

10 Antología II. pp. 287-288: «El derecho está dividido en dos partes, a saber: Derecho canónico y Derecho civil; y, por eso, Derecho canónico es derecho divino y Derecho civil es derecho terreno[...] Así como a los clérigos se les da el Derecho canónico, para que puedan atenerse a las reglas por que están en su oficio de clerecía, así a los príncipes se les da el Derecho civil».

Es de notar en este texto la limitación de destinatarios del derecho canónico. Lulio reduce el derecho canónico a un derecho puramente clerical, como si no afectara también a los fieles laicos. Quizá, lo que pretendía señalar con esa descripción era simplemente que el derecho canónico tenía su razón de ser en los clérigos y que estaba destinado primaria y directamente a los clérigos, lo cual sí está cerca de la realidad jurídico-canónica de aquel tiempo. En realidad, Lulio habla de cuatro modalidades de derecho (que Montserrat Quintana, p.178, reduce a tres: «En la Doctrina pueril amplía las ramas del derecho a tres -aunque en el original se hable de cuatro-»): derecho canónico-divino, derecho civil-terrenal, derecho para evitar otro mal mayor, y la "Quarta manera de dret es en lo dret canonic, lo qual se descové en la teorica e en la pratica». Pienso que, quizá, en este punto Lulio hace referencia a un derecho teológico-canónico (que sería «dret en la teorica») frente a un derecho meramente canónico, es decir, independizado de la teología en cuanto a su normatividad (que sería «dret en la pratica»). Tendríamos así normas de conducta teológicas y normas de conducta jurídica). Es, simplemente, una idea para explicar la división cuatripartita de Lulio. Decir que Lulio habla de cuatro modalidades, pero que, de hecho, son tres, no me parece una explicación satisfactoria. Están muy cerca unas divisiones de otras para dar por bueno que se deben a un despiste 0 a una confusión de Lulio. En realidad, Lulio presenta primero dos modalidades generales del derecho: canónico (divinal) y civil (terrenal); y luego, señala otras dos modalidades especiales, que enfrentan teoría y práctica, y que hallan su razón de ser en las disposiciones «positivas», que no siempre derivan, de hecho, del derecho natural, al que pueden no ajustarse totalmente. Ello se debe, en última instancia, a la malicia de las gentes.

11 Aunque también contempla parcial e indirectamente dicha posibilidad, ya que acepta que ese «tercer derecho» no coincide «exactamente con dicho concepto (el de derecho penal), que Llull define de manera harto oscura como el que tiene por objeto evitar el mal mayor y consentir el mal menor» (A. Montserrat Quintana, p. 178).

12 Podrían ser ejemplos las normas de la "guerra justa» y de la «pena de muerte» para ciertos casos.

13 En el Ars iuris, pars secunda, de septima regula, folio 10: «Intelligo per ius naturale Deum diligere, honeste vivere unicuique quod est suum reddere»; y pars tertia, quaestio prima, folio 14: «Principia iuris sunt: Deum diligere, honeste vivere, unicuique quod suum est tribuere», edición de Nicolaus Mayol et Cardell, Palma de Mallorca, p. 1745. Cf. Quintana, p. 180 y pp. 204-205.

14 El texto, hasta este punto, está tomado de san Isidoro, Ethimologiarum libri XX, lib.2, cap. 10, nn.4-5 y lib.5, cap. 19, n.1.

15 D.3 c.4, Ed. de Aemilius Friedberg, Graz 1959, col.5. 
Me ha llamado también la atención que Antonio Montserrat Quintana relacione entre los temas específicos de signo jurídico, junto a los de la libertad y la responsabilidad (que entran en las categorías jurídicas, pero que representan ante todo valores metajurídicos), el de la predestinación, de evidente contenido teológico-dogmático, pero no jurídico. ${ }^{16}$

Sólo un detalle más; la bibliografía utilizada es amplia, excede del ámbito de lo escrito sobre la teoría jurídica de Lulio para comprender el pensamiento luliano en toda su extensiọn, lo cual es acertado en un trabajo de esta clase; pero he echado en falta dos estudios de Eugen Wohlhaupter sobre Lulio jurista; ${ }^{17}$ si no he errado en mi lectura, a este autor solamente lo menciona por su artículo «Die Ars Brevis quae est de inventione mediorum iuris civilis de Ramon Llull». ${ }^{18}$

Pese a estas y a otras objeciones menores que cabría poner, A. Montserrat Quintana ha elaborado un estudio muy valioso; es, sin duda, el intento más amplio y mejor estructurado de penetrar hasta el fondo en el pensamiento jurídico luliano, de situar la visión luliana del mundo del derecho en el sistema científico de Lulio, en su «ars»; aunque me parece exagerada là afirmación, más amistosa que crítica, del prologuista Jaume Brufau i Prats, quien dice literalmente: «Ante el trabajo llevado a cabo, pensamos que, con la investigación del Dr. Montserrat, queda substancialmente cubierto el conocimiento del área filosófica-jurídica luliana. El pozo sin fondo del opus del Doctor Iluminado permitirá siempre volver sobre temas aquí tratados. Con todo, creemos que el contenido de lo roturado por Ramón Llull ha sido ya desvelado, en sus dimensiones esenciales, a lo largo de las páginas del presente libro». ${ }^{19}$

Estimo que la investigación de Antonio Montserrat Quintana constituye un primer estudio amplio y profundo sobre la visión luliana del derecho, estudio que servirá de apoyo e impulso a la realización de ensayos posteriores, de modo que no solamente se puede, sino que se debe ir más lejos en el estudio de Lulio como jurista. Justamente, uno de los méritos a destacar en la obra de Montserrat Quintana es la apertura de nuevas vías para futuras investigaciones sobre el pensamiento jurídico luliano.

Otros autores se han fijado en aspectos jurídicos concretos, especialmente en los relativos al derecho internacional: la paz (Mariano Puigdollers, Miguel Caldentey, Andrés de'Palma, Fermín de Urmeneta, Rafael Gibert, Gerardo $\mathrm{M}^{\mathrm{a}}$ Thomas) ${ }^{20}$ las doctrinas jurídicas internacionales (Andrés de

16 Quintana 35.

17 Referenciados ambos en la nota 2.

18 Publicado en Miscel-lània Lul-liana, Barcelona, 1935, pp. 36-55.

19 Montserrat Quintana, A., p. 8.

20 Puigdollers, M., «Doctrinas pacifistas de Raimundo Lulio en su relación con la comunidad internacional», en Anales de la Universidad de Valencia, 6 (1925-1926), pp. 208-222; Caldentey, M., «La paz y el arbitraje internacional en Raimundo Lulio», en Verdad y Vida, 1 (1943) pp. 456-485; de Palma, A., «El cardenal de la paz y la verdadera Sociedad de las Naciones, según el Beato. Ramón Lull», en XXXV Congreso Eucarístico Internacional 1952, Sesiones de Estudio, 2, Barcelona, (1953), pp. 544-554; de Urmeneta, F. «El pacifismo luliano», en Estudios Lulianos, 2 (1958) pp. 197-208; Gibert, R., «Raimundo Llull y la paz universal», en Estudios Lulianos, 10 (1966), pp. 153-170; Thomas Sabater, G.M., Consideraciones sobre las ideas de unidad y paz en el pensamiento jurídico de Ramón Llull, Palma de Mallorca, 1967. 
Palma, Konrad Schön, Rafael Bauzá), ${ }^{21}$ el poder temporal del papado (Antonio Oliver), ${ }^{22}$ la conexión de la teología con el derecho en la renuncia al papado y en la institución del cardenalato (Sebastián Garcías Palou), ${ }^{23}$ etc., destacando todos ellos la singularidad y originalidad del pensamiento luliano, pero sin detenerse, sin entrar a fondo en el análisis y fundamentación de las ideas jurídicas lulianas.

Parece que no resulta fácil adentrarse en las profundidades doctrinales de Raimundo Lulio, cuando menos en las profundidades jurídicas; quizás, porque el mismo Raimundo Lulio no llegó a ver con claridad suficiente todo lo relativo al mundo del derecho y no nos dejó un desarrollo del saber jurídico que se pueda seguir con lógica. Sabemos por confesión propia que no se sentía seguro en el ámbito de lo jurídico, y que, por ello, pedía la ayuda de los peritos para explicar la ciencia del derecho con la claridad que él deseaba. ${ }^{24}$ Quizás no resulta fácil, porque Raimundo Lulio no profundiza en la teoría jurídica y se conforma con aplicar al derecho, a su práctica, principios no estrictamente jurídicos, principios filosófico-teológicos, y lo que intenta es elaborar una metodología jurídica conforme a dichos principios. Y en ello es donde Lulio hace uso de su privilegiada inteligencia.

El tiempo en el que vive Raimundo Lulio es la época dorada del derecho, concretamente del derecho canónico. En la mente de todos están los nombres de grandes juristas y canonistas, entre los cuales se cuentan varios sumos pontífices. Incluso, el propio Lulio llegó a tener una relación especial con un canonista bien conocido, Raimundo de Peñafort, autor compilador del Liber Extra o Decretales del papa Gregorio IX, el corpus jurídico de mayor peso en la Iglesia hasta nuestros días.

Raimundo Lulio nos ha legado varias obras de derecho (Liber principiorum iuris, Ars iuris, Ars de iure = Ars iuris naturalis, Ars brevis iuris civilis), pero su pensamiento jurídico se halla también en otras obras no específicamente jurídicas, en Doctrina pueril, Blanquerna, Liber proverbiorum, Arbol de la ciencia, etc.

Tanto en sus escritos jurídicos como en sus referencias al derecho pone de manifiesto unos conocimientos no comunes en el ámbito del derecho canónico y civil. Otro problema es determinar hasta qué punto Raimundo Lulio fue capaz de (o quiso) conectar con el mundo del derecho de

21 D'Alós-Moner, R., «Idèes lul-lianes de comunitat universel», en Miscel-lània Patxot, Barcelona (1931) pp. 35-47; de Palma, A., «la doctrina jurídica i el sistema de dret internacional de Mestre Ramon Lull», en Miscel-lània Patxot, Barcelona (1931), pp. 407-432; Bauzá, R., «Doctrinas jurídicas internacionales de Ramón Llull», en Estudios Lulianos 2 , (1958) pp. 157-174; 3 (1959), pp. 181-184; 5, (1961), pp. 171-175 y pp. 295-304; 13, (1969), pp. 37-49; 14, (1970), pp. $37-45$.

22 Oliver, A., «El poder temporal del papa según Ramón Llull y postura de éste relativa a las controversias de su tiempo», en Estudios Lulianos 5, (1961), pp. 99-131.

23 Garcías Palou, S., «La renuncia del papa Blanquerna al papado (aspectos jurídico-teológicos del pensamiento luliano sobre la renuncia a la Sede Romana)»; «Aspectos teológico-jurídicos del pensamiento luliano sobre el cardenalato (un capítulo de la eclesiología medieval)», en Estudios Lulianos, 19 (1975), pp. 61-70; 21, (1977), pp. 69-83.

24 En el Arbol de la ciencia, 7.5 (cito por la Antología de Ramón Llull, vol.II, p. 557, traducción castellana de Alonso de Cepeda y Andrada, impresa en Bruselas el año de 1663), confiesa su contrariedad porque no dispone de la ayuda necesaria para un mejor conocimiento de la ciencia jurídica, que le permitiera una exposición clara de la misma: «iOh, qué gran daño es que no tenga yo coadjutores que me ayudasen a tratar del bien público! Porque, si los tuviera, conozco y. veo modo con el cual se dispondría con toda claridad la ciencia del derecho, que está tan confusa, y se podría saber en breve tiempo [...] Y por esto Ramón tuvo voluntad de tratar brevemente del modo general que pertenece a la ciencia del derecho, porque no podía por sí solo tratarlo completamente, por cuanto ignoraba las leyes y derechos particulares, y también por cuanto atendía más (bien a) a tratar de cosas más altas, y que son de mayor fin». 
su tiempo, y en qué sentido, con qué objetivos; es decir, surge el interrogante de si Raimundo Lulio se mantuvo al tanto de las ideas jurídicas de su tiempo y hasta qué punto le interesaron.

No tenemos datos sobre cómo, dónde, por cuánto tiempo, con qué maestros aprendió Lulio la ciencia jurídica que transmite en sus obras. En todo caso, se da por seguro que no llegó a recibir una formación jurídica universitaria; de hecho, no hay constancia de que cursase dichos estudios en Bolonia, Montpellier, París o en algún otro centro de enseñanza universitaria que incluyera las leyes y/o los cánones entre las miaterias a impartir. No obstante, se debe dar también por seguro que llegó a adquirir una formación singular en prácticamente todos los saberes. Lulio fue, sin duda, un fuera de serie, un sabio.

De otra parte, no deberíamos contentarnos con la idea de que los estudios generales fueron los únicos y los mejores «talleres» del saber. En relación, concretamente, al ámbito del derecho, no deberíamos olvidar la tradición jurídica hispana, ya desde épocas anteriores a Graciano, y la rápida y notable contribución de no pocos juristas hispanos a la glosa del Decreto (Vicente Hispano, Lorenzo Hispano, etc.), así como las compilaciones jurídicas de los principales reyes

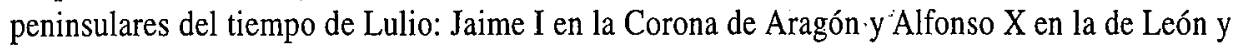
Castilla. Y, aunque todavía no esté suficientemente documentado y analizado, hay suficientes indicios para afirmar que los estudios jurídicos y las profesiones a que daban lugar (administradores, abogados, jueces, consejeros, etc.) estaban muy solicitadas en los reinos hispanos; 10 cual sería ciertamente imposible sin algún tipo de escolaridad, de aprendizaje ordenado y metódico. ${ }^{25}$

En concreto, ¿qué es el derecho, por qué existe el derecho, para qué es el derecho, según Raimundo Lulio?

Aunque el pensamiento luliano resulte a veces muy complejo y no se deban sacar conclusiones precipitadas a base de una frase o de una sentencia, me parece lógico suponer que Raimundo Lulio buscó una concordancia teórica, de ideas, de pensamiento, no sólo una concordancia metodológica. Por esta vía, me permito proponer que Lulio ve el derecho como una consecuencia del pecado, no como un bien en si. El derecho no existe simplemente porque el hombre es un ser social «ubi societas jbi ius», el derecho existe porque no hay caridad. El derecho no tiene, pues, sentido por sí mismo, como reflexión; su existencia se debe al egoísmo, a la falta de caridad. De ahí derivan tensiones entre poder y derecho, entre normas y libertad. El derecho se justifica como instrumento para realizar la justicia, que es su objetivo, y la paz, consecuencia de la justicia. El poder es la mano del derecho para realizar esa justicia y esa paz aplicando rectamente las normas jurídicas. ${ }^{26}$

25 A finales del siglo XII, el teólogo Martino de León, en sus Sermones o Veteris ac Novi Testamenti Concordia (conjunto de escritos teológicos en forma de lecciones) se queja amargamente de la abundancia y del dinamismo de los juristas de las curias. Y poco después, a principios del siglo XIII, Antonio de Lisboa se pronuncia en términos parecidos con respecto a los decretistas y demás juristas. Para ambos autores, Cf. Soto Rábanos, J. M., «Condicionamiento jurídico canónico de Martino de León y línea pastoral martiniana», en Isidoriana, 1: Santo Martino de León, León (1987), pp. 627653; «Formación jurídica en Antonio de Lisboa», en Congresso Internacional Pensamento e Testemunho. Actas, II, Braga (1996) pp. 765-783.

26 Montserrat Quintana, A., pp. 182-185, lo ve también así, aun cuando el hecho de que el derecho tenga su raíz en la falta de caridad en la ideología de Raimundo Lulio, no le lleva a sacar otras conclusiones en esa vía de necesidad secundaria, negativa, del fenómeno jurídico. 
Sin escatimar su demostrada gran capacidad de abstracción, Lulio es caracterizado por su realismo, por su pragmatismo, por su deseo de simplificación, de la reductio ad unum, ad Deum, que es la verdad, de la que su ars, su método, es el camino, es el libro. ${ }^{27}:$ :

El mundo del derecho no puede separarse en ningún modo de tạ realidad material de la vida humana, la cual solamente halla explicación racional suficiente, según Raimundo Lulio, en la fe cristiana y desde la fe cristiana.

Fijado este punto de partida, que somete a meditación pero no a crítica, en cuanto que la aceptación del mismo no se discute aunque se razone, ${ }^{28}$ de lo que se trata es de elaborar el método mejor para hacerla comprender, de modo que sea aceptada por todos desde la razón como fe verdadera. Con esta finalidad, inventa su «arte», un método de combinación y simplificación.

Otro aspecto a tener en cuenta al analizar el pensamiento de Lulio sobre el derecho es el conocimiento y la admiración que muestra por los usos jurídicos árabes cuya funcionalidad alaba y desea sea imitada en la cristiandad. Esa funcionalidad conecta con el reconocido pragmatismo luliano, antes mencionado. ${ }^{29}$

Ya en esta línea, cabe preguntarse hasta qué punto Raimundo Lulio estuvo influido por ciertas ideas de la filosofía árabe en torno a la separación entre la razón y la fe, entre la filosofía y la religión. Su racionalización de la fe, su intento de llegar a Dios por razones necesarias, le lleva a algunas aseveraciones, en las que parece entreverse una cierta influencia en el sentido indicado de separar la fe racional de la fe ruda, del creer por creer (fe del carbonero). Posiblemente, haya cierta influencia, pero parece que Lulio salva el escollo de una separación radical mediante el recurso superior a la fe, a la iluminación, de modo que la verdad que busca y; por ende, su arte, no deriva en última instancia de un razonamiento, sino de una iluminación; la fe será siempre una gracia, no una conquista de la razón. ${ }^{30}$ En el caso del propio Lulio, Dios le ha iluminado para construir y exponer las razones necesarias de la fe. Con razón se le llamará «doctor iluminado». ${ }^{31}$

27 Lulio caracteriza a los filósofos por el uso que hacen de los cinco sentidos corporales, no simplemente por su capacidad de abstracción; por su lógica más que por su ontológica (Cf. Montserrat Quintana, A. pp. 30-31).

De otra parte, Lulio quiere escribir, no un libro más, sino el libro mejor del mundo (Vida coetánea $6=$ Antología I.54-55), el libro de la verdad; quiere llegar a expresar la verdad, no simplemente a creerla y a pensarla. Las razones necesarias que fabrica y expone se hacen sensibles, corpóreas, se materializan a través de su método combinatorio.

Lulio es, además, profunda y radicalmente teocrático. Lo es, al menos, en el ámbito jurídico. De ahí, su voluntad de reducir todo el derecho a Dios, como fuente primaria y última del mismo. En Blanquerna, libro IV, expone su deseo de comunidad universal, con unidad de derecho, de costumbres, de lengua, de pensamiento y de fe; y asimismo en el Libro del gentil y de los tres sabios, en cuyo prólogo exclama: « ¡Y qué gran felicidad sería ésta si, por estos árboles pudiésemos estar bajo una ley y una creencia todos los hombres que existimos![...]; Y que[...] todos los pueblos que existen se uniesen en ser un pueblo tan sólo[...] y que todos juntos tuvieran una fe y una ley y tributasen gloria y alabanza a Dios Nuestro Señor!» (Antología II, p. 384).

28 Es decir, que la verdad de la fe cristiana no se somete a discusión.

29 Cf. Montserrat Quintana, A., pp. 43-44 y 168.

30 Cf. Eijo Garay, L., «La supuesta heterodoxia del beato Llull», en Estudios Lulianos, 12 (1968), pp. 5-19; Bauzá, M., «Ramón Lull en el Enchiridion Symbolorum de Heinrich Danzinger», ibid. pp. 21-32.

31 Vida coetánea, n. 14 (Antología 1. 58-59): «Ocurridas estas cosas subió Ramón a una montaña, no muy lejos de su casa, para poder allá contemplar con más sosiego a Dios; y habiendo permanecido en ella casi ocho días, ocurrió un día, mientras se hallaba absorto mirando los cielos, que de pronto el Señor ilustró su mente, concediéndole manera y forma de escribir el libro de que más arriba se habla contra los emrores de los infieles». 
El racionalismo luliano se fundamenta en el modo de entender el conocimiento teológico como precepto, que implica una actitud activa frente al dato revelado, al estilo de la reflexión árabe, que no se conforma con el taqlid, es decir, la mera recepción del dato revelado, sino que precisa del nazar, o sea, de la recepción activa, racional, del precepto bíblico, del dato revelado. ${ }^{32}$

Desde el punto de vista del derecho, la separación entre lo racional y la fe, entre filosofía y religión, hubiera llevado a la separación del derecho respecto de la filosofía moral y de la teología; y justamente, lo que defiende Lulio es la reducción de lo jurídico a lo filosófico-moral, a los principios teológicos y del derecho natural; $y$, en última instancia, a la verdad de su arte, que es como decir a Dios. Lulio está convencido de que sus escritos contienen «rationes cogentes» para la aceptación de la fe; incluso se muestra pretencioso equiparando en este punto sus libros a la «sacra pagina». ${ }^{33}$

Como anoté anteriormente, Lulio no quería escribir un libro simplemente, un libro más, sino el libro mejor del mundo. ${ }^{34}$ Me pregunto si lo que quería escribir era, en realidad, una especie de nueva Biblia, adaptada a las necesidades del momento en cuanto a la formulación de las verdades eternas; si no fue ese su deseo, cuando menos, así lo parece.

Pienso que estas observaciones aplicadas al derecho, como esse ad, como una relatio, refuerzan la impresión, que se tiene desde que se inicia el análisis de la doctrina jurídica luliana, de que Lulio no se interesa a fondo por la teoría del derecho, sino por la práctica; le interesa la implantación recta de la justicia a nivel individual y social.

En mi opinión, y a expensas de interpretaciones mejores, al contrario de como se interesa con respecto a la teología y a la filosofía, materias en las que se adentra en reflexiones básicas, en el ámbito de lo jurídico, Raimundo Lulio deja esas reflexiones básicas para los jurisperitos. Y no porque carezca de formación jurídica suficiente para elaborarlas, que demuestra tenerla y no débil, sino porque no le interesa la verdad meramente teórica del derecho, que podría permanecer ociosa y/o llevar a la injusticia de hecho; le interesa la verdad práctica, una verdad objetivada, que entra por los sentidos; una verdad (jurídica en el caso) que conlleva atención, laboriosidad. ${ }^{35}$

Por otra parte, no se puede perder de vista que Raimundo Lulio tiende a la congregación de todas las ciencias en su ars, como tiende a la congregación de todas las cosas en Dios; y esto se consigue a través de su método. Todas las consideraciones son instrumentales para el resultado buscado.

32 En este sentido se expresa Gayà, J., «El conocimiento teológico como precepto, según R. Llull», en Estudios Lulianos, 18 (1974), pp. 47-51.

33 Liber de fine, I.4-5 (Raimundi Lulii Opera Latina, t.IX. Ed. Aloisivs Madre, Corpus Christianorum. Continuatio Mediaevalis 35, Turnholt, Brepols, (1981), pp. 266-267): «Et ideo Dominus papa et domini etiam cardinales hoc multum debent timere, quoniam propter defectum ecclesiae schismata sunt in mundo; quae possent destrui, si dominus papa et domini cardinales uolebant facere ea, quae in hoc uolumine continentur» $(\mathrm{I} .4<266>)$; «[...] Et ideo, si religiosus ille de nostra fide tales dedisset rationes ita cogentes, quod rex non posset soluere ante dictas quae rationes sunt in sacra pagina implicatae; et sum certus etiam, quod in libris meis supra dictis sunt, ut patet in eisdem tunc rex fuisset christianus, et una cum eo suae gentes» $(\mathrm{I} .5<267>)$.

34 Véase nota 27.

35 En Doctrina pueril 76.4, Lulio deja notar su menor, su casi nulo interés por la teoría jurídica propiamente dicha (no me refiero aquí a las bases filosófico-teológicas en las que se apoya Lulio para elaborar su arte, sea éste aplicado al derecho o a cualquier otra ciencia): «Alguna cosa es derecho en la teoría y su contrario es derecho en la práctica». De otra parte, no deja de llamar la atención el puesto preeminente que Lulio concede a la virtud de la laboriosidad frente al puesto de peor vicio que otorga a la ociosidad. La acción frente a la inacción (Ibid., 91). Cf. Sala-Molins, L., «Le postulat fondamental de la philosophie lullienne», en Estudios Lulianos, 14 (1970), pp. 181-198, acerca de la primacía de la acción sobre el ser en la filosofía luliana. 
Aplicado esto al derecho significa que la ciencia jurídica, fuera de que tenga su propia naturaleza, su propio modo de ser, no interesa a Lulio si no en cuanto cree que es instrumentalmente necesaria para la realización de la justicia.

En todo caso, se puede decir que Lulio manifiesta tener un buen conocimiento de la ciencia jurídica y un conocimiento muy pormenorizado de la práctica jurídica, pero que no le interesa en absoluto la discusión de la temática jurídica. De ahí que se mantenga al margen de glosas y comentarios, de comentaristas y glosadores.$^{36}$ Le interesan los grandes conceptos, los principios elementales que le permiten construir su mecanismo, su método de aplicación simple y objetiva de la justicia, que es el objeto del derecho. ${ }^{37}$

Resulta significativo, en todo caso, que Raimundo Lulio no haga consideraciones teóricoprácticas sobre tal o cual norma; que no haya escrito ninguna ğlosa, ningún comentario a una ley o a un canon, ni desde la perspectiva de la fundamentación de la norma, ni desde la perspectiva de su aplicabilidad. ${ }^{38}$ Es como si Lulio no quisiera entrar de propio intento en el sistema jurídico vigente, por no hallar en él la perfección que busca. Un detalle deja ver su indiferencia, ya que no su ignorancia, al respecto. El derecho canónico es para Lulio un derecho divino para la ordenación del clero. ${ }^{39}$ Aunque es cierto que el derecho canónico se orienta mayoritariamente al clero, si tenemos en cuenta la cantidad relativa de las normas que le afectan, y más entonces, su destinatario era y es el pueblo cristiano. Y como tal, no se puede afirmar sin más explicación que el derecho canónico sea un derecho divino, aun siendo evidente su conexión con la teología y con la revelación divina.

La ciencia jurídica es para Raimundo Lulio confusa, prolija y difícil, basada más en la memoria que en el entendimiento, una ciencia práctica más que teórica. ${ }^{40}$

36 Eugen Wohhhaupter considera a Raimundo Lulio un precursor de los postglosadores. («Ramon Lull und die Rechtswissenschaft», Ernst Majer Festschrift, Weimar (1932), pp. 198-202; «Ramon Lull, ein vorläufer des postglossatoren», Atti del Congresso Internazionale per il Diritto Romano, Bologna-Roma, aprile 1933, Pavia (1934), pp. 491-514.

37 Montserrat Quintana, A., pp. 191-201, aporta abundantes citas y extensas reflexiones sobre là relación derechojusticia-paz en Lulio.

38 Sí manifiesta su disconformidad con la aplicación de las leyes por los propios profesionales de la justicia y del derecho: jueces, procuradores, abogados, que juzgan intuitu personae y no por igual a unos y a otros, alargan los pleitos y los encarecen, prevarican, etc. Cf. Doctrina pueril 76.4; Árbol de la Ciencia 7.5; Libre de Contemplació en Deu 114.3; Libre de Sancta Maria 12; Blanquerna 4.90.

39 Doctrina pueril, 76.2 (Obres doctrinals I.136): «En axí com als clergues es donat dret canonich per so que pusquen la regla seguir per la qual son en uffici de clerecía, en axí als prínceps es donat dret civil per so que seguesquen la regla per la qual son estabilits e exalsats sobre los altres homens». En versión castellana (Antología II.288): «Así como a los clérigos se les da el Derecho canónico, para que puedan atenerse a las reglas por que están en su oficio de clerecía, así a los príncipes se les da el Derecho civil, para que observen la regla por que han sido puestos y levantados sobre los demás hombres».

40 Es significativa la insistencia de Raimundo Lulio en esta consideración del derecho como ciencia confusa, prolija, difícil: «Quoniam scientia iuris est valde prolixa et difficilis eo quia est de particularibus multis[...]» «Quoniam vita hominis est brevis et scientia iuris est multum prolixa[...]» (así empiezan el Ars de iure y el Ars iuris); «Bonum et magnum etc. est, quod scientia iuris reducatur ad syllogismos, quia confusa est et prolixa» (Liber de ente $9=$ Raimundi Lvlli Opera Latina, t.VIII. Edidit Hermogenes Harada, Corpus Christianonum. Continuatio Mediaevalis 34, Turnhout, Brepols, (1980), p. 244). Ello no obsta para que el derecho sea, según Lulio, una ciencia importante. En realidad, es una de las cuatro que considera elementales, por este orden: teología, filosofía, medicina y derecho; pero todos estos saberes (como bien señala A. Montserrat Quintana, pp. 247-251) se subordinan a la teología. 
Las actividades jurídicas, las actuaciones de los jueces, del foro, las relaciones entre personas y entidades, a nivel bilateral, local, nacional, internacional e interreligioso, le parecen prolijas y demasiado complejas.

Pero estos actos jurídicos, generalmente tan complejos y llenos de confusión, se pueden simplificar, insertándolos en el arte combinatorio propio, es decir, en el adecuado al mundo del derecho. De esta manera, las actuaciones jurídicas en todas sus vertientes serán más objetivas y más simples; y en consecuencia, más justas y más económicas. Los principios fundamentales están dados; basta recogerlos, someterlos a su método combinatorio y aparece la solución a la cuestión planteada. ${ }^{41}$

Aunque en la base hay un razonamiento jurídico (la selección de los principios aplicables conlleva un razonamiento), Lulio no pretende discutir o reflexionar en profundidad sobre la esencia, la razón de ser o el por qué del derecho. Realmente, ni siquiera es necesario; los principios aplicables están ahí, en la Biblia y en las enseñanzas teológicas y filosóficas defendidas por la Iglesia católica, en las que se basa el iusnaturalismo luliano.

Los escritos jurídicos de Lulio tienen como finalidad la enseñanza de su método a los juristas, pero al tiempo pide ayuda a los peritos en derecho para poder explicarlo con claridad, de modo que pueda aprenderse en poco tiempo. ${ }^{42}$

Raimundo Lulio cree poder tomar toda la realidad de cada rama científica, someter los datos todos de esa realidad a las oportunas y correspondientes combinaciones mediante la aplicación de reglas generales de valor universal aceptadas previamente como indiscutibles y llegar así, por razones necesarias, a la solución del problema planteado.

Su metodología jurídica es puramente utópica; viene a ser una mecanización de la puesta en acto de la justicia ajustada a un modo particular, y cerrado, de considerar la justicia y su aplicación. Raimundo Lulio pretende una resolución objetivada de la problemática jurídica.

Para Lulio la ciencia del derecho dejaría de ser confusa y prolija si se redujera a la filosofía moral, es decir, reducendo ipsam ad principia innata primitiua, uera et necessaria. ${ }^{43}$ Esto es casi

41 Raimundo Lulio no parece consciente de que el formalismo jurídico (con su formulismo inherente) es, esencialmente, una consecución positiva para la aplicación más justa de las leyes, que se exige justamente con el propósito de conseguir una mayor seguridad jurídica, aun cuando en la práctica no siempre sirva bien a su finalidad e, incluso, a veces, la contradiga.

42 ¿Es éste un rasgo de humildad o reconocimiento de no ser un conocedor experto, un profesional, del derecho? Sea lo que fuere, esta confesión implícita de impericia no se aviene bien con la opinión de A. Montserrat Quintana sobre el saber jurídico de Lulio, de quien afirma que muestra un profundo conocimiento del derecho, no sólo desde el punto de vista de la filosofía del derecho, sino también en cuanto a los conocimientos prácticos y a cuestiones complejísimas concretas (p. 35). Lo cierto es que Raimundo Lulio, que demuestra un buen conocimiento del derecho, no se considera a si mismo un perito en derecho. De alguna forma, sus obras jurídicas le avalan como un «artista» del derecho, que es su pretensión en este campo como en los demás campos del saber y del creer, de la ciencia y de la fe. Quizás no fue un «perito» en ningún terreno concreto del saber, pero demuestra que fue un «artista» en todos aquellos de los que se ocupó. En todo caso, fue, ciertamente, un sabio por la amplitud de sus conocimientos y, en algunos puntos, por la profundidad de su pensamiento.

43 Liber de ente 9 (Raimundi Lvlli Opera Latina, t.VIII. Ed. Hermogenes Harada, Corpus Christianorum. Continuatio Mediaevalis 34, Turnhout, Brepols, (1980), p. 244: «Bonum, magnum etc. est, quod scientia iuris reducatur ad sillogismos, quia confusa est et prolixa. Et hoc fieri potest per illum modum, quem fecimus in uno libro, qui uocatur Ars iuris, reducendo ipsam ad principia innata primitiva, uera et necessaria». 
una voluntad de negación del derecho, con referencia al derecho positivo emanado del poder temporal, ya que éste debería reducirse a positivar el derecho natural, como se contiene en su ars. Evidentemente, Raimundo Lulio juega a la utopía. Y no parece que el ámbito de lo jurídico sea el único en el que Lulio muestra su tendencia (su querencia) a la utopía. ${ }^{44}$

En términos generales, yo diría que, si bien Raimundo Lulio propone algo irrealizable y, en definitiva, inútil en cuanto a la conquista de la meta final propuesta: aprehender la «Verdad», asirla racionalmente, tiene un gran mérito, porque abre el campo del discurso racional hacia argumentos nuevos, hacia una dinámica filosófica distinta de la escolástica y, en algunos aspectos, tan valiosa como la propia escolástica. En el intento del hombre por razonar sus creencias siempre hay un grado importante de utopía (un poco al aire de la anécdota agustiniana de querer meter toda el agua del mar en un hoyito de la playa); pero, en el caso de Raimundo Lulio, la utopía se hace más evidente, pues en su método no usa simplemente del argumento abstracto, inmaterial, sino que utiliza también la mecánica, la ciencia práctica, los artificios materiales, todo cuanto nos entra por los sentidos corporales, la vista y el oído especialmente. Extraigo la conclusión general de que para aceptar como viable el «arte» luliano, no sólo hay que ser creyente; además, hay que ser lulista.

José María Soto Rábanos

C.S.I.C.

Duque de Medinaceli, 6.

28014. Madrid

44 Sobre este aspecto cf. Maurice de Gandiliac, «De quelques utopies (ou semiutopies) de la concorde universelle» (Abelard, Lulle, Nicolas de Cues, Postel, Campanella), en Miguel Martínez López (ed.), Literature, Culture and Society of the Middle Ages, IX: Studies in honour of Ferran Valls i Taberner, Barcelona (1989), pp. 2583-2598; en especial, pp. 2586-2589. 